\title{
Rumination and its relationship to feeding and lying behavior in Holstein dairy cows
}

\author{
K. Schirmann, ${ }^{\star} \dagger$ N. Chapinal, ${ }^{*}$ D. M. Weary, ${ }^{*}$ W. Heuwieser, $†$ and M. A. G. von Keyserlingk ${ }^{\star 1}$ \\ *Animal Welfare Program, Faculty of Land and Food Systems, The University of British Columbia, 2357 Main Mall, Vancouver, \\ BC, V6T 1Z4, Canada \\ †Clinic for Animal Reproduction, Faculty of Veterinary Medicine, Freie Universität Berlin, Königsweg 65, 14163 Berlin, Germany
}

\section{ABSTRACT}

The objective of this study was to describe the relationship between rumination and feeding and lying behavior in dairy cows. Rumination time was monitored electronically using HR-Tags (SCR Engineers Ltd., Netanya, Israel). Feeding time and dry matter intake (DMI) were monitored using Insentec feed bins (Insentec BV, Marknesse, the Netherlands). All measures were collected in 2 -h periods for 42 mature Holstein cows for a minimum of $9 \mathrm{~d}$ in the early dry period. Pearson correlation was used to describe associations, among 2-h periods within cow, first examining the relationship within a single period, and then modeling how this relationship changes when a lag of 2,4 , or $6 \mathrm{~h}$ was imposed. Periods when cows spent more time ruminating were associated with lower feeding times and lower DMI ( $\mathrm{r}=-0.71$ and $\mathrm{r}=-0.72$, respectively), likely because cows were unable to feed and ruminate simultaneously. The correlations with rumination time changed from negative to positive when lags of 2,4 , and $6 \mathrm{~h}$ were modeled $(\mathrm{r}=-0.09,0.24$, and 0.15 , and $\mathrm{r}=-0.16,0.23$, and 0.17 for feeding time and DMI at lags of 2,4 , and $6 \mathrm{~h}$, respectively). These results indicate that following periods of high feeding times and intakes, cows spent more time ruminating. This relationship peaks at approximately $4 \mathrm{~h}$ after feeding. Periods of rumination were also associated with time spent lying down. Cows that spent more time ruminating per day, spent less time feeding $(\mathrm{r}=-0.34)$ and rumination times did not relate to DMI $(\mathrm{r}=0.11)$. These data indicate that rumination time can be used to estimate within-cow variation in feeding behavior and intake, but daily summaries of rumination behavior are a poor indicator of DMI.

Key words: feeding time, dry matter intake, welfare, automated assessment

Received July 18, 2011.

Accepted February 12, 2012.

${ }^{1}$ Corresponding author: marina.vonkeyserlingk@ubc.ca

\section{INTRODUCTION}

Rumination is a natural behavior for ruminants; it is required to break down the size of feed particles so that they can pass through the reticulo-omasal orifice (Welch, 1982). Also, it is essential in providing rumen bacteria greater access to feed particles during microbial fermentation (Russell and Rychlik, 2001). Rumination has long been associated with health in dairy cattle (Radostits et al., 2007) and, more recently, changes in rumination have been used to assess the responses of dairy cattle to acute stressors (Bristow and Holmes, 2007; Schirmann et al., 2011) and disease (DeVries et al., 2009). It has also long been assumed that cows preferentially ruminate when lying down, but we are not aware of empirical evidence supporting this relationship. Lying times in lactating dairy cattle also follow a diurnal pattern, inverse to that of feeding behavior (Fregonesi et al., 2007).

Previous work on rumination has focused almost exclusively on the effects of nutritional treatments (e.g., Krause et al., 2002) and digestion of forages (Beauchemin, 1992). Some authors (e.g., Hasegawa et al., 1997) have assumed a strong relationship between rumination time and DMI, suggesting that rumination times may be used to assess DMI. One study (Krause et al., 2002) found a positive relationship between long particle DMI and rumination time, but otherwise little experimental evidence exists supporting the link and no work showing the temporal relationship between intakes and rumination. On a daily basis we might expect a positive relationship between intakes and rumination, because higher intakes may require more rumination time to process. At a more instantaneous level of analysis, we might expect a negative association, as cows cannot eat and ruminate at the same time. Instead we expect that rumination will peak in the hours following a feeding bout, but the timing of this relationship has not been studied.

Diurnal patterns of rumination have been described for heifers (Jaster and Murphy, 1983) and lactating dairy cows (Krause et al., 2002; Adin et al., 2009), but no work to date has focused on prepartum cows. 
Nonlactating dairy cows are typically fed and managed differently than lactating cows. Time of feed delivery (DeVries et al., 2003; DeVries and von Keyserlingk, 2005), feed push-up (DeVries et al., 2003) and milking (DeVries et al., 2003; Adin et al., 2009) all influence when cows feed and likely also when they ruminate. We, therefore, expected differences in the diurnal patterns of both feeding and rumination behavior between nonlactating cows used in the current work and lactating cows studied previously.

The objective of the current study was to describe the diurnal pattern of rumination in prepartum dairy cows and determine how this pattern relates to DMI, times spent feeding and times spent lying down. Furthermore, we were interested in investigating the use of rumination time as a predictor for DMI. On a daily basis, we predicted a positive relationship between time spent ruminating and DMI and feeding time. On an hourly basis, we expected a negative association between rumination and feeding time and DMI, and a positive relationship between rumination time and lying time.

\section{MATERIALS AND METHODS}

\section{Animals, Housing, and Diet}

A total of 48 mature nonlactating Holstein dairy cows (parity $=2.2 \pm 1.4$; mean $\pm \mathrm{SD}$ ) were used (as described in Schirmann et al., 2011). Cows were enrolled at $40 \pm 8 \mathrm{~d}$ (mean $\pm \mathrm{SD}$ ) before their expected calving date and had been dry for $21 \pm 10 \mathrm{~d}$ (mean \pm $\mathrm{SD}$ ). The behavior of each cow was recorded for $16 \mathrm{~d}$. The study was conducted between November 2008 and January 2009 at the University of British Columbia's Dairy Education and Research Centre (Agassiz, BC, Canada). Animals were cared for according to guidelines of the Canadian Council on Animal Care (1993).

Cows were housed in groups of 6 in 2 experimental pens and both pens were used simultaneously. These pens were separated by a nonexperimental pen of similar design. All pens measured $10.2 \mathrm{~m} \times 13 \mathrm{~m}$, and were equipped with 6 Insentec feed bins (Insentec BV, Marknesse, the Netherlands), 1 Insentec water bin, and 12 lying stalls in 2 rows of 6 , fitted with a mattress (Pasture Mat; Promat Inc., Woodstock, Ontario, Canada) covered with approximately $5 \mathrm{~cm}$ of washed river sand. Cows were provided access to only 3 of the 6 feed bins, resulting in a cow-to-feed bin ratio of 2:1. The Insentec system was programmed to allow all cows to access all 3 feed bins and the water bin. Cows were allowed access to 1 of the 2 rows of 6 stalls by blocking the 6 stalls at the back, resulting in a cow-to-stall ratio of 1:1.
Cows were fed a TMR (Table 1) formulated according to the recommendations of the NRC (2001). Cows were fed ad libitum and fresh feed was provided twice daily at approximately $0800 \pm 1 \mathrm{~h}$ and $1600 \pm 1 \mathrm{~h}$. Feed samples were collected twice weekly, at the time of fresh feed delivery, from both pens and then pooled. The samples were stored in a freezer and then thawed and dried at $60^{\circ} \mathrm{C}$ for $48 \mathrm{~h}$ to determine the DM content. For nutrient analysis, the dried samples were sent to Cumberland Valley Analytical Services Inc. (Maugansville, $\mathrm{MD})$ and analyzed according to the standards of the Association of Official Analytical Chemists (AOAC, 2005 ) to determine average $\mathrm{CP}, \mathrm{ADF}, \mathrm{NDF}$, and $\mathrm{NE}_{\mathrm{L}}$ content of the feed fed throughout the study (Table 1). Thawed samples were also used to evaluate particle size of the TMR using the Penn State Particle Separator (Kononoff et al., 2003) consisting of 3 sieves and the bottom pan. The pore sizes of the 3 sieves were $19 \mathrm{~mm}$ (upper sieve), $8 \mathrm{~mm}$ (middle sieve), and $1.3 \mathrm{~mm}$ (lower sieve). The TMR was composed of $42.4 \pm 6.2 \%$ (mean $\pm \mathrm{SD}$ ) particles $>19 \mathrm{~mm}, 34.4 \pm 5.4 \%$ of particles $>8$ $\mathrm{mm}, 19.4 \pm 2.1 \%$ of particles $>1.3 \mathrm{~mm}$, and $3.8 \pm 0.7 \%$ of particles $<1.3 \mathrm{~mm}$. Particle lengths are reported for descriptive purposes only.

\section{Behavioral Recording}

Rumination Behavior. All cows were fitted with an individual rumination logger (HR-Tag; SCR Engineers Ltd., Netanya, Israel) on a neck collar to record rumination time. The rumination logger continuously records the time spent ruminating within $24 \mathrm{~h}$ in 2 -h intervals, as validated by Schirmann et al. (2009). For

Table 1. Ingredients and nutrient composition of the TMR fed throughout the study ${ }^{1}$

\begin{tabular}{lcc}
\hline Composition & $\begin{array}{c}\text { Amount } \\
\text { as fed \% }\end{array}$ & \% of DM \\
\hline Diet ingredient & & \\
Grass silage & 43.6 & \\
Corn silage & 39.7 & \\
Straw & 12.7 & \\
Mineral and concentrate mix & 4.0 & \\
Chemical composition & & \\
CP & & $15.1 \pm 1.4$ \\
ADF & $32.2 \pm 3.3$ \\
NDF & $53.1 \pm 4.6$ \\
NE $(\mathrm{Mcal} / \mathrm{kg})$ & $1.43 \pm 0.7$ \\
Ash & & 9.6 \\
Starch & & 7.8 \\
Ca & & 0.56 \\
P & & 0.33 \\
Mg & & 0.29 \\
K & & 2.5 \\
\hline
\end{tabular}

${ }^{1}$ Data were averaged from feed samples taken twice weekly. 
data transfer, automatic readers, as part of the same system, were located above the water bins.

Feeding Behavior. The Insentec system (Insentec BV), previously validated by Chapinal et al. (2007), was used to record individual feed intake and time spent feeding. The Insentec system used each cow's radio frequency identification (RFID) to record each time each cow placed her head into the feed bin, and calculated the total duration of the feeder visit as well as the amount of feed consumed during that visit. The recorded feed intake and the measured DM content were used to calculate DMI. The durations of each feeder visit were summed to calculate total feeding time by day and by 2 -h interval within day.

Lying Behavior. All cows were fitted with an activity logger (HOBO Pendant G; Onset Computer Corp., Cape Cod, MA) to record the frequency of lying bouts and their duration as validated by Ledgerwood et al. (2010). The data logger was attached to either hind leg of each cow and programmed to record position of the cow, lying or standing, once per minute.

\section{Data Analysis}

All statistical analyses were performed with SAS (version 9.1; SAS Institute, 2003). Data were summarized by cow and 2 -h interval, and by cow and day. Data from d 0 to 2 relative to regrouping was not considered in the analysis because regrouping was found to affect behavior (Schirmann et al., 2011). Days with incomplete data due to technical problems were discarded. Only animals with at least $9 \mathrm{~d}$ of data $(\mathrm{n}=42$ animals for rumination and feeding behavior, $\mathrm{n}=35$ animals for lying behavior) were included in the final analyses. Diurnal patterns are presented for descriptive purposes only. Pearson correlation (PROC CORR) was used to assess the relationship between rumination time and DMI, feeding time and lying time on a daily and a $2-\mathrm{h}$ period basis. Correlations on a daily basis were estimated across cows (data within cow was averaged across days) and within cows. Correlations on a 2 -h interval basis were calculated within cow only. Rumination time for each 2-h period was correlated to DMI and feeding time corresponding to the same 2-h interval as well as to each of the 3 previous 2 -h periods (i.e., considering 2 , 4,6 , and $8 \mathrm{~h}$ difference between feeding and rumination behavior). Within-cow correlation coefficients were not normally distributed and, thus, the Fisher z transformation was applied before estimating a mean correlation coefficient across cows. Means were tested against 0 by using a $t$-test (PROC UNIVARIATE). Within-cow coefficients are expressed as back-transformed means and $95 \%$ confidence interval.

\section{RESULTS}

\section{Diurnal Pattern}

Time spent feeding and DMI peaked immediately after morning and afternoon feed delivery and coincided with a decrease in time spent ruminating and lying (Figure 1A-D). Time spent ruminating was highest at night and between feedings during the day.

\section{Correlation by Day}

Across cows, a negative relationship was observed between average daily rumination time and feeding time ( $\mathrm{r}=-0.34, P=0.03)$, but no relation between daily rumination time and DMI $(\mathrm{r}=0.11 ; P=0.48)$ or lying time $(\mathrm{r}=0.02 ; P=0.9)$. Within cows, a weak negative correlation was observed between daily rumination time and daily DMI (Table 2), and a weak positive relationship with lying time $(\mathrm{r}=0.13 ; 95 \% \mathrm{CI}=0.001$, $0.25 ; P=0.047)$. No relationship existed between daily rumination time and daily feeding time (Table 2).

\section{Correlation by 2-h Intervals}

When tested on a 2-h interval basis, we found negative relationships between rumination time and feeding time and DMI (Table 2), and a positive relationship with lying time $(\mathrm{r}=0.60 ; 95 \% \mathrm{CI}=0.53,0.65 ; P<$ $0.0001)$. After adding a 2 -h lag, rumination time and DMI and feeding time were still negatively correlated, but these correlations were positive when using a lag of $4 \mathrm{~h}$. After a 6-h lag these correlations weakened and no correlation existed when using an 8-h lag.

\section{DISCUSSION}

To our knowledge, this is the first study to describe diurnal patterns of rumination over an extended period and to show how these are related to patterns of feeding and lying behavior. Overall, the diurnal pattern for rumination time in this study was similar to that previously described by Deswysen et al. (1989) for dairy heifers; both studies showed that cattle spend more time ruminating at night than during the day. The diurnal pattern for feeding behavior agrees with findings of DeVries et al. (2003) and Hosseinkhani et al. (2008), showing 2 peaks in DMI and time spent feeding. These peaks are largely influenced by the time of fresh feed delivery, and are known to change in response to feeding frequency (DeVries et al., 2003). The pattern of lying behavior observed for the dry cows used in this study was similar to that previously reported for lactat- 

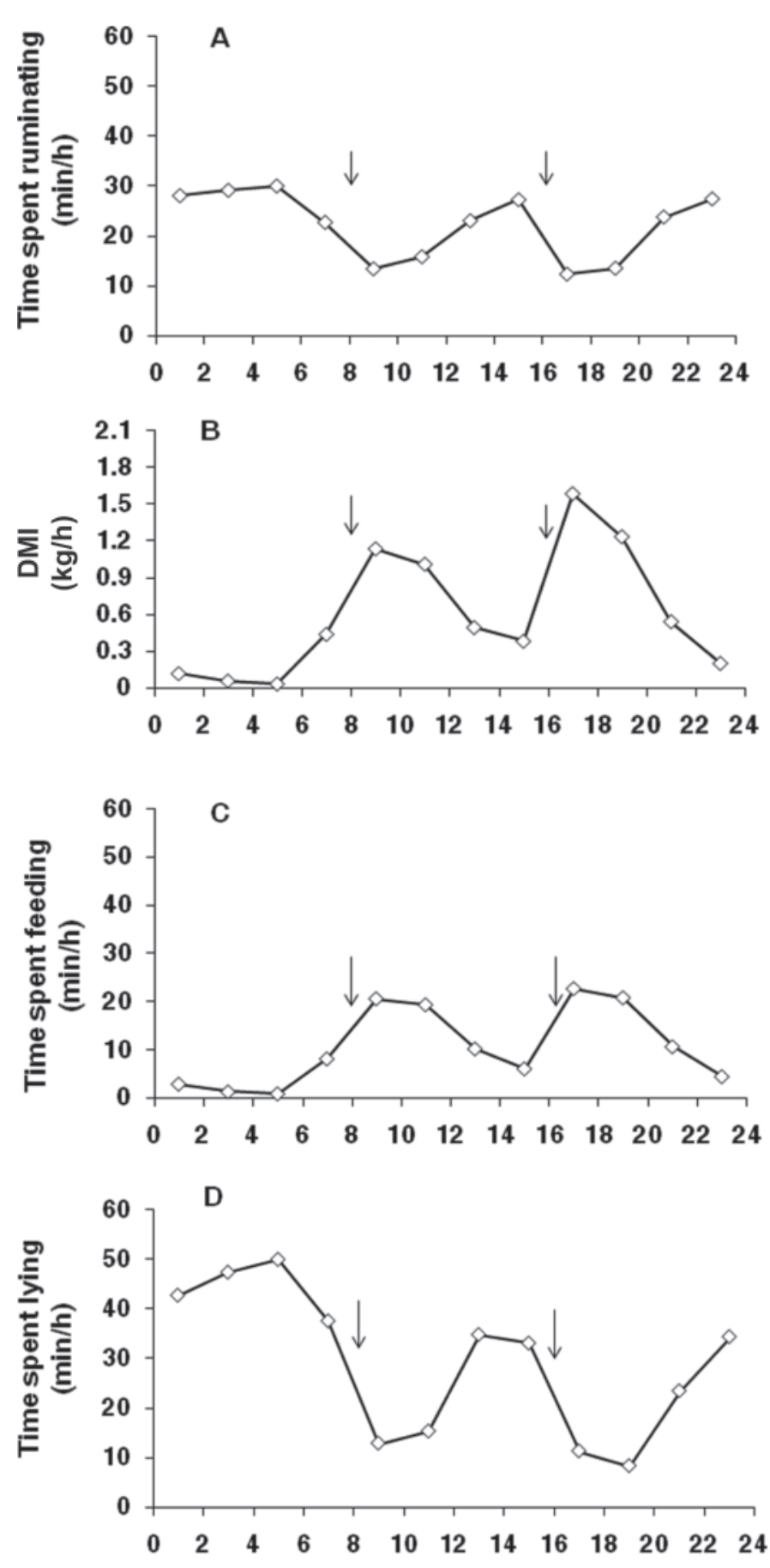

\section{Hour of day (h)}

Figure 1. Diurnal pattern (mean) for rumination time (A), DMI (B), feeding time (C), and lying time (D) for prepartum multiparous dairy cows fed a TMR twice daily (approximately 0800 and $1600 \mathrm{~h}$; indicated with arrows $\downarrow$ ). $\mathrm{n}=42$ cows for rumination time, DMI, and feeding time; $\mathrm{n}=35$ cows for lying time. ing dairy cows (Fregonesi et al., 2007), with the lowest lying time corresponding to peaks in feeding behavior.

Across cows, we observed no correlation between daily rumination times and daily DMI or lying time. The high degree of variation in DMI and time spent ruminating between and within cows and days (Welch, 1982; Harb and Campling, 1985; Dado and Allen, 1994) may have affected our findings. We did, however, note a negative correlation between daily rumination time and feeding time, suggesting that the cows that ruminate more spent less time feeding. Cows are not able to consume feed and ruminate at the same time, perhaps explaining this negative correlation.

We found a much stronger negative relationship between rumination time and feeding time when tested by 2-h interval, and also found a strong negative correlation between rumination time and DMI when tested by 2 -h interval. These results again are likely driven by cows not being able to ruminate while consuming feed. The shift from a negative to a positive relationship between rumination time and DMI or time spent feeding when imposing the 4-h lag can be explained by a delay in the onset of rumination following ingestion of feed (Hedlund and Rolls, 1977).

The positive within-cow correlation between rumination time and lying time on a 2-h interval basis indicates that periods of rumination are more frequent when cows are lying down; this agrees with the commonly held belief that rumination and lying behavior are associated (Beauchemin, 1991). The relationship between these measures is far from perfect, in part because cows lie down without ruminating and in part because some rumination occurs while cows are standing. Future work would benefit from continuous records of both behaviors to better illustrate the nature of the relationship.

\section{CONCLUSIONS}

Our data show no relation between rumination time and DMI across cows, and only a weak negative relationship among days within cows observed during the dry period. These results indicate that the use of daily rumination times to estimate DMI is limited. Within a 2-h period, a strong negative association exists between rumination and both DMI and feeding time, indicating that cows spend little time ruminating during peak feeding periods. Rumination times are positively associated with DMI and feeding times after a 4-h lag, indicating that peak rumination times lag intake by approximately this time. Rumination and lying times are positively associated, helping to explain why rumination peaks at night when cows are most likely to be 
Table 2. Pearson correlation coefficients for the within-cow analysis by day and by 2 -h interval between time spent ruminating and DMI $(\mathrm{n}=42)$ and time spent ruminating and feeding time $(\mathrm{n}=42)$, considering no lag, 2-h, 4-h, 6-h, and 8-h lag between feeding and rumination behavior ${ }^{1}$

\begin{tabular}{|c|c|c|}
\hline Parameter & $\mathrm{r}(95 \% \mathrm{CI})$ & $P$-value \\
\hline \multicolumn{3}{|l|}{ By day } \\
\hline DMI (kg/d) & $-0.18(-0.29,-0.07)$ & 0.002 \\
\hline Time spent feeding $(\mathrm{min} / \mathrm{d})$ & $-0.05(-0.17,0.07)$ & 0.40 \\
\hline \multicolumn{3}{|l|}{ By interval } \\
\hline \multicolumn{3}{|l|}{ No lag } \\
\hline DMI (kg/2 h) & $-0.72(-0.75,-0.69)$ & $<0.001$ \\
\hline Time spent feeding $(\min / 2 \mathrm{~h})$ & $-0.71(-0.75,-0.68)$ & $<0.001$ \\
\hline \multicolumn{3}{|l|}{ 2-h lag } \\
\hline DMI $(\mathrm{kg} / 2 \mathrm{~h})$ & $-0.16(-0.22,-0.11)$ & $<0.001$ \\
\hline Time spent feeding $(\min / 2 \mathrm{~h})$ & $-0.09(-0.15,-0.04)$ & 0.002 \\
\hline \multicolumn{3}{|l|}{ 4-h lag } \\
\hline DMI $(\mathrm{kg} / 2 \mathrm{~h})$ & $0.23(0.20,0.27)$ & $<0.001$ \\
\hline Time spent feeding $(\min / 2 \mathrm{~h})$ & $0.24(0.20,0.28)$ & $<0.001$ \\
\hline \multicolumn{3}{|l|}{6 -h lag } \\
\hline DMI (kg/2 h) & $0.17(0.15,0.21)$ & $<0.001$ \\
\hline Time spent feeding $(\min / 2 \mathrm{~h})$ & $0.15(0.11,0.18)$ & $<0.001$ \\
\hline \multicolumn{3}{|l|}{8 -h lag } \\
\hline DMI $(\mathrm{kg} / 2 \mathrm{~h})$ & $0.02(-0.02,0.06)$ & 0.27 \\
\hline Time spent feeding $(\min / 2 \mathrm{~h})$ & $-0.01(-0.05,0.03)$ & 0.55 \\
\hline
\end{tabular}

${ }^{1}$ Coefficients were normalized by applying Fisher's z transformation. Data are presented as back-transformed means and $95 \%$ CI. Means were t-tested against 0.

lying down (and least likely to be feeding). However, we caution the extrapolation of our results to lactating dairy cattle, as our observations were limited to cows during the dry period. We strongly encourage future work to monitor DMI and rumination behavior on dairy cattle at various stages of lactation consuming rations differing in forage type and concentration.

\section{ACKNOWLEDGMENTS}

We thank the staff of The University of British Columbia (UBC) Dairy Education and Research Centre and the University's Animal Welfare Program (Vancouver, BC, Canada). In particular, we thank Doug Veira (Agriculture and Agri-Food Canada, Ottawa, ON, Canada) and Mohammad Khan, Lindsay Collings, and Lori Vickers (UBC Animal Welfare Program) for their support. We also thank William Sears (Department of Population Medicine, University of Guelph, Guelph, ON, Canada) for statistical advice. K. Schirmann was funded by a scholarship from Tiergyn Berlin e.V. (Berlin, Germany). This research is supported by Canada's Natural Sciences and Engineering Research Council Industrial Research Chair Program (Ottawa, ON, Canada) with industry contributions from the Dairy Farmers of Canada (Ottawa, ON, Canada), Westgen (Milner, BC, Canada), Pfizer Animal Health (Kirkland, QC, Canada), BC Cattle Industry Development Fund (Kamloops, BC, Canada), the BC Milk Producers (Burnaby, BC, Canada), BC Dairy Foundation (Burnaby, BC, Canada), BC Dairy Industry Research and Education Fund (Abbotsford, BC, Canada), and Alberta Milk (Edmonton, AB, Canada).

\section{REFERENCES}

Adin, G., R. Solomon, M. Nikbachat, A. Zenou, E. Yosef, A. Brosh, A Shabtay, S. J. Mabjeesh, I. Halachmi, and J. Miron. 2009. Effect of feeding cows in early lactation with diets differing in roughageneutral detergent fiber content on intake behavior, rumination, and milk production. J. Dairy Sci. 92:3364-3373.

AOAC. 2005. Official Methods of Analysis. 18th rev. ed. Association of Official Analytical Chemists, Arlington, VA.

Beauchemin, K. A. 1991. Ingestion and mastication of feed by dairy cattle. Vet. Clin. North Am. Food Anim. Pract. 7:439-463.

Beauchemin, K. A. 1992. Effects of ingestive and ruminative mastication on digestion of forage by cattle. Anim. Feed Sci. Technol. 40:41-56.

Bristow, D. J., and D. S. Holmes. 2007. Cortisol levels and anxietyrelated behaviors in cattle. Physiol. Behav. 90:626-628.

Canadian Council on Animal Care. 1993. Guide to the Care and Use of Experimental Animals. Vol. 1. E. D. Olfert, B. M. Cross, and A. A. McWilliam, ed. Canadian Council on Animal Care (CCAC), Ottawa, Ontario, Canada.

Chapinal, N., D. M. Veira, D. M. Weary, and M. A. G. von Keyserlingk. 2007. Technical note: Validation of a system for monitoring individual feeding and drinking behavior and intake in grouphoused dairy cattle. J. Dairy Sci. 990:5732-5736.

Dado, R. G., and M. S. Allen. 1994. Variation in and relationships among feeding, chewing, and drinking variables for lactating dairy cows. J. Dairy Sci. 77:132-144.

Deswysen, A. G., P. A. Dutilleul, and W. C. Ellis. 1989. Quantitative analysis of nycterohemeral eating and ruminating patterns in heifers with different voluntary intakes and effects of monensin. J. Anim. Sci. 67:2751-2761.

DeVries, T. J., K. A. Beauchemin, F. Dohme, and K. S. SchwartzkopfGenswein. 2009. Repeated ruminal acidosis challenges in lactating dairy cows at high and low risk for developing acidosis: Feeding, ruminating, and lying behavior. J. Dairy Sci. 92:5067-5078. 
DeVries, T. J., and M. A. G. von Keyserlingk. 2005. Time of feed delivery affects the feeding and lying patterns of dairy cows. J. Dairy Sci. 88:625-631.

DeVries, T. J., M. A. G. von Keyserlingk, and K. A. Beauchemin. 2003. Short communication: Diurnal feeding pattern of lactating dairy cows. J. Dairy Sci. 86:4079-4082.

Fregonesi, J. A., C. B. Tucker, and D. M. Weary. 2007. Overstocking reduces lying time in dairy cows. J. Dairy Sci. 90:3349-3354.

Harb, M. Y., and R. C. Campling. 1985. Variation among pregnant, non-lactating dairy cows in eating and ruminating behaviour, digestibility and voluntary intake of hay. Grass Forage Sci. 40:109111.

Hasegawa, N., A. Nishiwaki, K. Sugawara, and I. Ito. 1997. The effects of social exchange between two groups of lactating primiparous heifers on milk production, dominance order, behavior and adrenocortical response. Appl. Anim. Behav. Sci. 51:15-27.

Hedlund, L., and J. Rolls. 1977. Behavior of lactating dairy cows during total confinement. J. Dairy Sci. 60:1807-1812.

Hosseinkhani, A., T. J. DeVries, K. L. Proudfoot, R. Valizadeh, D. M. Veira, and M. A. G. von Keyserlingk. 2008. The effects of feed bunk competition on the feed sorting behavior of close-up dry cows. J. Dairy Sci. 91:1115-1121.

Jaster, E. H., and M. R. Murphy. 1983. Effects of varying particle size of forage on digestion and chewing behavior of dairy heifers. J. Dairy Sci. 66:802-810.

Kononoff, P. J., A. J. Heinrichs, and D. R. Buckmaster. 2003. Modification of the Penn State forage and total mixed ration particle separator and the effects of moisture content on its measurements. J. Dairy Sci. 86:1858-1863.

Krause, K. M., D. K. Combs, and K. A. Beauchemin. 2002. Effects of forage particle size and grain fermentability in midlactation cows. II. Ruminal pH and chewing activity. J. Dairy Sci. 85:1947-1957.

Ledgerwood, D. N., C. Winckler, and C. B. Tucker. 2010. Evaluation of data loggers, sampling intervals, and editing techniques for measuring the lying behavior of dairy cattle. J. Dairy Sci. 93:5129-5139.

NRC. 2001. Nutrient Requirements of Dairy Cattle. 7th rev. ed. National Academy Press, Washington, DC

Radostits, O. M., C. C. Gay, K. W. Hinchcliff, and P. D. Constable. 2007. Page 268 in Veterinary Medicine: A Textbook of the Diseases of Cattle, Horses, Sheep, Pigs and Goats. 10th ed. Saunders Ltd., Philadelphia, PA.

Russell, J. B., and J. L. Rychlik. 2001. Factors that alter the rumen microbial ecology. Science 292:1119-1122

SAS Institute. 2003. SAS User's Guide. Version 9.1. SAS Institute Inc., Cary, NC.

Schirmann, K., N. Chapinal, D. M. Weary, W. Heuwieser, and M. A. G. von Keyserlingk. 2011. Short-term effects of regrouping on behavior of prepartum dairy cows. J. Dairy Sci. 94:2312-2319.

Schirmann, K., M. A. G. von Keyserlingk, D. M. Weary, D. M. Veira, and W. Heuwieser. 2009. Technical note: Validation of a system for monitoring rumination in dairy cows. J. Dairy Sci. 92:6052-6055.

Welch, J. G. 1982. Rumination, particle size and passage from the rumen. J. Anim. Sci. 54:885-894. 